\title{
PbS - Nanoparticles Embedded in Polymer Matrix: Preparation and Characterization
}

\author{
P. K. Singh ${ }^{1, *}$, S. K. Tomar $^{2}$, B. Bhattacharya ${ }^{1}$ \\ ${ }^{1}$ Material Research Laboratory, Department of Physics, School of Engineering \& Technology, Sharda University, G. Noida, 201306, India \\ ${ }^{2}$ IET, JK Lakshmipat University, Jaipur, Rajasthan, India
}

\begin{abstract}
Formation of nano-sized $\mathrm{PbS}$ in $\mathrm{PEO}$ - polymer matrix at room temperature is being reported. SEM showed the particle size distribution while TEM affirmed the formation of nano particulates of $\mathrm{PbS}$. The size distribution was further supported by UV/VIS absorption of the colloid. At room temperature a wide variation in the size of the particles was observed depend on sulfuration and salt concentration. The detailed characterization of these nano - $\mathrm{PbS}$ doped in polymer electrolyte are also discussed.
\end{abstract}

Keywords Pbs Nanopartciles, Polymer Electrolytes, SEM, TEM

\section{Introduction}

Small inorganic semiconductor crystallites in the form of colloids have attracted researchers due to their very interesting properties[1]. The experimental verification of the transformation between molecular and bulk properties in small aggregates is being highly persuaded. Large number of studies has been reported so far on the formation of nano crystallites of semiconductors in zeolite and polymer matrix as well[2-5]. The various properties of nano-crystals has become the topic of both theoretical[6,7] and experimental interest[8-12]. In most of the studies, nano-crystalline semiconductors belonging to the II-VI group have been taken up while the studies related to IV-VI are rather scanty. $\mathrm{PbS}$ is an important member of this family. It is one of the earliest materials studied for its interesting photoconductive properties which has been exploited by many researchers[13]. The basic problem associated with colloidal semiconductors like $\mathrm{CdS}, \mathrm{PbS}$ is that the lifetime of the photogenerated electron/hole pair is very short. Therefore, for fast electron transfer reactions, a very high concentration of reagents is required. However, such high concentrations destabilize the colloid. In order to prevent such a stability problem, dispersion of colloids into polymer matrix is a novel alternative. Keeping this thing in mind we have doped the nano- $\mathrm{PbS}$ paricles into an ion conducting polymeric matrix. The polymer electrolyte chosen for the present study is PEO: $\mathrm{NH}_{4} \mathrm{I}(80: 20)$ which is predominantly a proton conducting polymer electrolyte[14,15] and maintain good

* Corresponding author:

singhpk71@gmail.com ( P. K. Singh )

Published online at http://journal.sapub.org/nn

Copyright (C) 2011 Scientific \& Academic Publishing. All Rights Reserved ionic conductivity and mechanical stability.

\section{Experimental}

To prepare polymeric membranes dispersed with semiconductor, Pure PEO (Mol. wt. $6 \times 10^{5}$, Aldrich) was dissolved in dehydrated methanol to which stoichiometric ratio of anhydrous $\mathrm{NH}_{4} \mathrm{I}$ (purity, Aldrich) was added to give PEO: $\mathrm{NH}_{4} \mathrm{I}$ weight ratio as $80: 20$. This solution was thoroughly stirred at $400 \mathrm{C}$ for 5 hours for complete complexation. After that we added a dilute solution of lead acetate to it drop by drop. As soon as the drop falls, $\mathrm{H}_{2} \mathrm{~S}$ was bubbled through the viscous solution (at $30 \mathrm{ml} . / \mathrm{min}$.) for 2-3 minutes which resulted in the formation of $\mathrm{PbS}$. A fresh $\mathrm{Pb}$-acetate drop was added and sulfuration was done as above.This continued till the desired weight ratio of $\mathrm{Pb}$-acetate gets added.The bubbling rate (sulfuration) was controlled by flowmeter. Colloidal particles of $\mathrm{PbS}$ was formed in PEO-matrix by following reaction

$$
\mathrm{Pb}\left(\mathrm{CH}_{3} \mathrm{COO}\right)_{2}+\mathrm{H}_{2} \mathrm{~S} \rightarrow \mathrm{PbS}+2 \mathrm{CH}_{3} \mathrm{COOH}
$$

The desired weight percent of $\mathrm{Pb}$-acetate salt $(1,5,10 \mathrm{wt} \%)$ and bubbling rate of $\mathrm{H}_{2} \mathrm{~S}(30,60,120 \mathrm{ml} / \mathrm{min}$.) were varied to obtain the different films. This PbS-dispersed polymer electrolyte viscous solution was poured into petri dishes for solution casting into film form. After drying it in room ambient for several days, the film were finally dried under vacuum to eliminate all traces of solvent. These nano- $\mathrm{PbS}$ embedded in polymer matrix were characterized with JEOL JSM-5800 LV scanning electron microscope, PHILLIPS TEM instrument (Model EM-CM 12). The band gap of the dispersed $\mathrm{PbS}$ was evaluated by UV/visible absorption spectra using Hitachi (model U-3400) spectrophotometer. For calculation of the energy band gap the equation, as given below, was employed 
$\alpha h v=A\left(h v-E_{g}\right)^{n}$

where ho denotes the energy of the incoming photon in electron volt, $\alpha$ is the absorption coefficient of the material, Eg is the energy band gap, $\mathrm{A}$ is a constant and the exponent $\mathrm{n}$ is $1 / 2$ for direct band gap materials[16].

\section{Results and Discussions}

To confirm the presence/formation of lead sulfide we have recorded the XRD diffraction patterns of PbS doped polymer films. The known prominent peaks of bulk $\mathrm{PbS}$ are at $2 \theta=26.1$ and 30.3. Unfortunately, near these angles some PEO-peaks are also present and it is difficult to distinguish. Hence, we carried out XRD measurement at a slow scan rate. A typical XRD pattern in the range $2 \theta=24-32^{0}$ is shown in figure 1 for films containing 5 and $10 \mathrm{wt} \%$ of $\mathrm{PbS}$. The results of an approximate deconvolution of these peaks into peaks assigned either to $\mathrm{PEO}$ or $\mathrm{PbS}$ are also shown in figure1. The dominant particle sizes determined from this data using Scherrer formula[17] are lies between 10-15 nm. The SEM photographs of different (PEO: $\left.\mathrm{NH}_{4} \mathrm{I}\right)+\mathrm{PbS}$ films with different composition and sulfuration are given in figure 2. It was obvious from the comparison of figures $2 \mathrm{a}$ and $2 \mathrm{~b}$ that more was the amount of $\mathrm{Pb}$-acetate in the starting solution, bigger aggregated $\mathrm{PbS}$ gets dispersed.

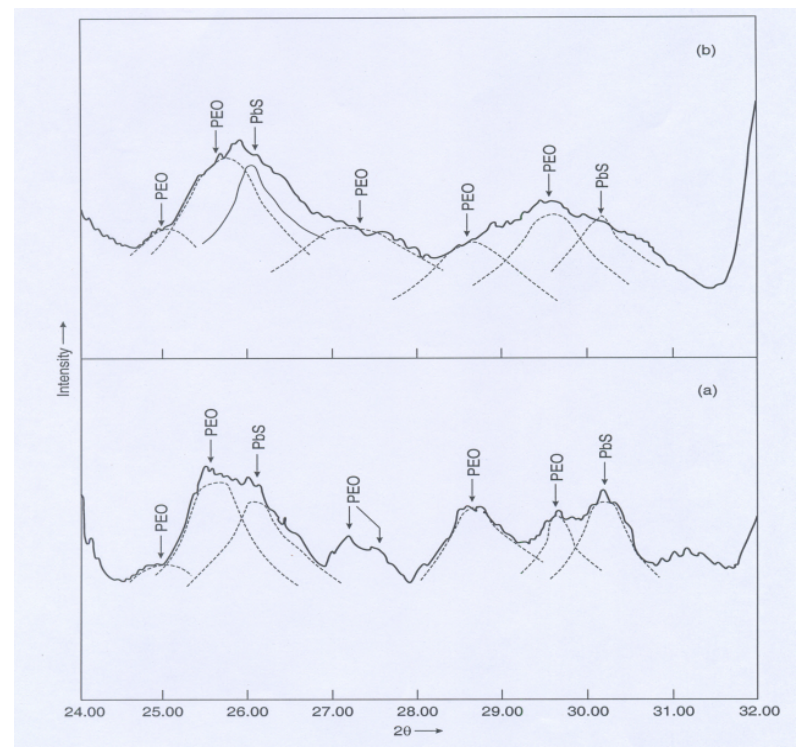

Figure 1. The deconvoluted $\mathrm{XRD}$ peaks of $\left(\mathrm{PEO}: \mathrm{NH}_{4} \mathrm{I}\right)+\mathrm{PbS}$ composite membrane containing (a) $5 \mathrm{wt} \%$ and (b) $10 \mathrm{wt} \%$ of $\mathrm{PbS}$

Further the bubbling rate of $\mathrm{H}_{2} \mathrm{~S}$ which controls the rate of sulfuration resulting in the formation of $\mathrm{PbS}$. When bubbling rate was $30 \mathrm{ml} / \mathrm{min}$., particles of small size are observed (figure 2a). When we increase the bubbling rate $(120 \mathrm{ml} / \mathrm{min}$.) larger particulates of $\mathrm{PbS}$ are observed (figure 2c). From these micrographs we can conclude that for obtaining small particles we must keep low salt concentration and low sulfuration rate. It was also clear that the dispersed $\mathrm{PbS}$ particles changes with the amount of salt $\mathrm{Pb}\left(\mathrm{CH}_{3} \mathrm{COO}\right)_{2}$ in the polymeric solution and bubbling rate of $\mathrm{H}_{2} \mathrm{~S}$. Our SEM could see only larger particles (less than 10 micron) and hence TEM study was used to evaluate the exact particle size of $\mathrm{PbS}$ crystallites/clusters, particularly of those which had nm-size. The TEM micrograph of a typical (PEO: $\left.\mathrm{NH}_{4} \mathrm{I}\right)+5 \mathrm{wt} \% \mathrm{PbS}$ film at $60 \mathrm{ml} / \mathrm{min}$. are shown in figure 3 . There was an obvious size distribution in micrograph showing small $(3-5 \mathrm{~nm})$ as well as large particle/clusters $(30-50 \mathrm{~nm})$ of PbS. Interestingly these $\mathrm{PbS}$ nanoparticles are well interconnected forming a channel which probably assisted in the transportation of ionic conduction. The small particles (nano-size) play an important role in the "size quantization effect" and hence change in the absorption spectra of the polymer film as discussed in the later section.

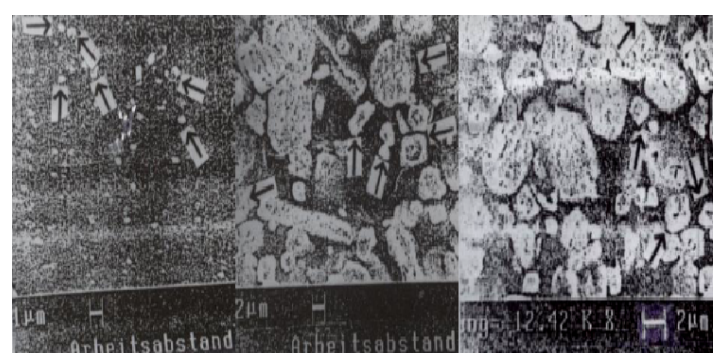

(a)

(b)

(c)

Figure 2. SEM micrographs of (a) (PEO:NH4I) +1 wt $\% \mathrm{PbS}$ (b) (PEO:NH4I)+5 wt $\% \mathrm{PbS}$ at $30 \mathrm{ml} / \mathrm{min}$. and (c) (PEO:NH4I)+1 $\mathrm{wt} \% \mathrm{PbS}$ at $120 \mathrm{ml} / \mathrm{min}$. polymer electrolyte films

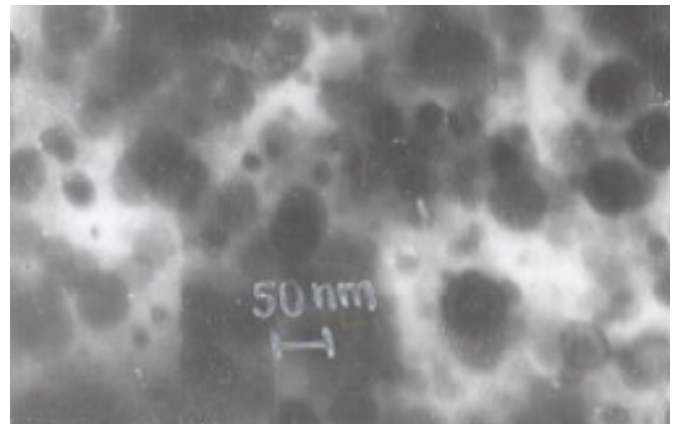

Figure 3. TEM micrograph showing size distribution of $\mathrm{PbS}$ nanoparticles in polymeric matrix

It is reported that the band gap of a specific material does not only depend on its structure but the size also has a controlling factor. Once the particle reaches nano-meter size, quantum effects come into play and the effective band gap increases[18-20]. The experimental determination of band gap of $\mathrm{PbS}$ from the optical absorption presented some problems. The band gap for bulk $\mathrm{PbS}$ is $\sim 0.37$ to $0.42 \mathrm{eV}$ which puts the absorption edge in the wavelength region $3300-2800 \mathrm{~nm}$, but in this region the interference from strong $\mathrm{H}_{2} \mathrm{O}$ bonds introduced ambiguity. If the particle size of $\mathrm{PbS}$ decreases $(\leq 5 \mathrm{~nm})$ the band gap may change to $1.2 \mathrm{eV}$ to 3.5 $\mathrm{eV}$ (visible/UV region). For reconfirmation of nano size distribution, we have recorded the absorption spectra of $\mathrm{PbS}$-doped polymer in the visible region (800-450 $\mathrm{nm}$.). The UV/visible absorption spectra of a typical PEO: $\mathrm{NH}_{4} \mathrm{I}+1 \mathrm{wt} \%$ $\mathrm{PbS}$ film prepared at $120 \mathrm{ml} / \mathrm{min}$. is shown in figure 4 . It was obvious that the absorption was continuously increasing in the $800-450 \mathrm{~nm}$. region. Based on this absorption spectra we 
have evaluated the band gap $\left(\mathrm{E}_{\mathrm{g}}\right)$ from the intercept on hv axis of $(\alpha h v)^{2}$ Vs hv plot shown in figure 5 .

It may, however, be noted that there is no sudden change in absorbance because of simultaneous presence of particles of all sizes (and hence different values of $E_{g}$ ). More then one intercept on hv axis (and hence different values of $E_{g}$ ) are clearly seen in figure 5 . The band gap evaluated varies from $1.9 \mathrm{eV}$ to $2.2 \mathrm{eV}$ reconfirms the formation of nano particulates which was supported by TEM study.

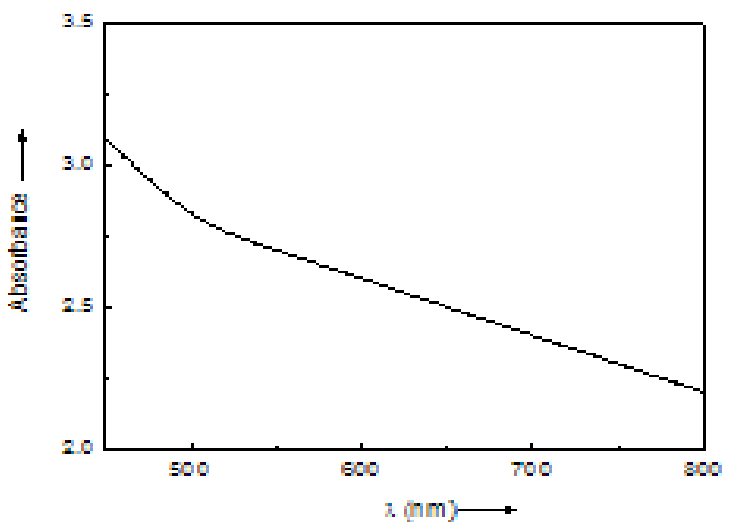

Figure 4. The absorption spectra of $\mathrm{PEO}: \mathrm{NH}_{4} \mathrm{I}+1 \mathrm{wt} \% \mathrm{PbS}$ polymer electrolyte film prepared at $120 \mathrm{ml} / \mathrm{min}$

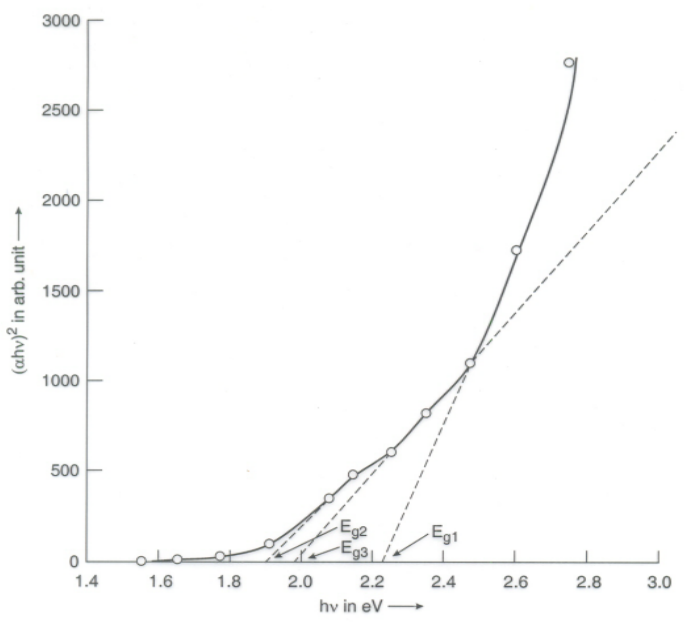

Figure 5. The $(\alpha h v)^{2}$ Vs hv plot of PEO:NH4I $+1 \mathrm{wt} \% \mathrm{PbS}$ polymer electrolyte film prepared at $120 \mathrm{ml} / \mathrm{min}$

Wagner's polarization method was used to measure the ionic \& electronic transference number of $\left(\mathrm{PEO}: \mathrm{NH}_{4} \mathrm{I}\right)+\mathrm{PbS}$ polymeric membranes using formula.

$$
t_{\text {ion }}=\left(1-t_{e}\right)=i_{T}-i_{f} / i_{T}
$$

where $t_{\text {ion }}$ is the ionic transference number, $i_{T}$ is the initial total current (due to ion + electron) and $\mathrm{i}_{\mathrm{f}}$ is the final saturation current due to the electrons only. The current Vs time plots are shown in figure 6 for different samples of (PEO: $\left.\mathrm{NH}_{4} \mathrm{I}\right)+\mathrm{x} \mathrm{PbS}(\mathrm{x}=1,5,10 \mathrm{wt} \%)$ prepared at $\mathrm{H}_{2} \mathrm{~S}$ bubbling rate of $120 \mathrm{ml} / \mathrm{min}$. along with the data for pure PEO: $\mathrm{NH}_{4} \mathrm{I}(\mathrm{x}=0)$ film. Similar curves were obtained for samples prepared at 30 and $60 \mathrm{ml} / \mathrm{min}$. bubbling rate. The calculated values of ionic transference number $\left(t_{\text {ion }}\right)$ are listed in table 1. It is well know that if the material is purely ionic in nature the ionic transference number $\mathrm{t}_{\mathrm{ion}} \sim 1$. From this table it is clear that our PbS-doped polymer films was mixed (ionic + electronic) conductor in nature and nearly $20 \%$ electronic conductivity could be introduced. The a.c. measurement of electrical conductivity is done (figure not shown here) to avoid polarization in the solid electrolytes. Here we have used the well known impedance spectroscopic technique to evaluate the true bulk conductivity. The values of total conductivity $\left(\sigma_{\mathrm{T}}\right)$; ionic conductivity $\left(\sigma_{\mathrm{I}}=\mathrm{t}_{\mathrm{ion}} \cdot \sigma_{\mathrm{T}}\right)$; electronic conductivity $\left(\sigma_{\mathrm{e}}=\mathrm{t}_{\mathrm{e}}, \sigma_{\mathrm{T}}\right)$ and $\mathrm{t}_{\text {ion }}$ are calculated using above said formulas.

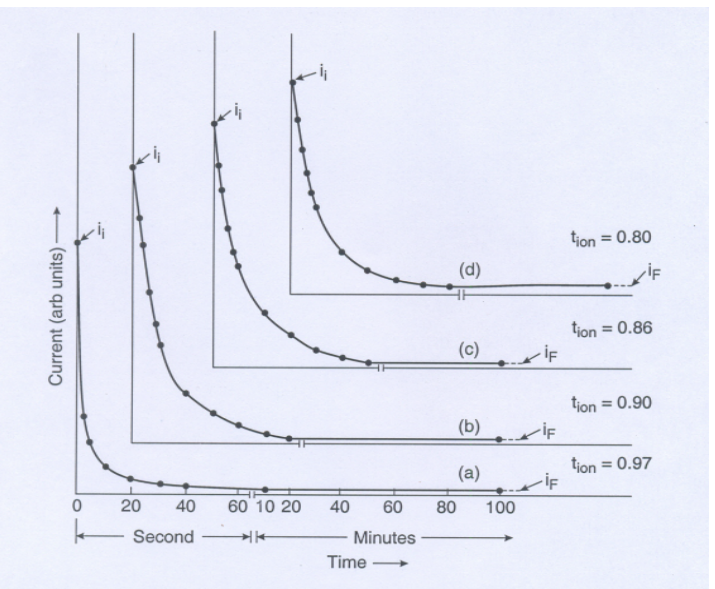

Figure 6. Polarization curves showing the current variation with time for different PEO: $\mathrm{NH}_{4} \mathrm{I}$ polymer electrolytes with (a) no $\mathrm{PbS}$ (b) 1 wt \% PbS (c) $5 \mathrm{wt} \% \mathrm{PbS}$ (d) $10 \mathrm{wt} \% \mathrm{PbS}$. at $120 \mathrm{ml} / \mathrm{min}$. bubbling rate.

Table 1. Calculated values of $t_{\text {ion }}$ for $\left(\mathrm{PEO}: \mathrm{NH}_{4} \mathrm{I}\right)+\mathrm{PbS}$ polymer films using Wagner's polarization method

\begin{tabular}{|c|c|c|c|}
\hline $\begin{array}{c}\text { Composition } \\
\text { (wt } \% \text { of } \mathrm{Pb} \text { salt) }\end{array}$ & $\begin{array}{c}\mathrm{t}_{\text {ion }} \text { at } 120 \\
\mathrm{ml} / \mathrm{min} .\end{array}$ & $\begin{array}{c}\mathrm{t}_{\text {ion }} \text { at } 60 \\
\mathrm{ml} / \mathrm{min} .\end{array}$ & $\begin{array}{c}\mathrm{t}_{\text {ion }} \text { at } 30 \\
\mathrm{ml} / \mathrm{min} .\end{array}$ \\
\hline 1 & 0.90 & 0.93 & 0.95 \\
5 & 0.86 & 0.88 & 0.90 \\
10 & 0.80 & 0.85 & 0.88 \\
\hline
\end{tabular}

Some important observations based on electrical characterization are summarized below

(i) The increase in $\sigma_{\mathrm{T}}$ is not only due to the increased $\sigma_{\mathrm{e}}$ but there is, as well, a substantial increase in $\sigma_{\mathrm{I}}$ due to interface effect present in the ionic composite systems.

(ii) The maximum $\sigma_{\mathrm{e}}$ is for the film prepared at "high" bubbling rates as expected since such a condition gives a low band gap $\mathrm{PbS}$ (bigger particulates).

(iii) The $\sigma_{\mathrm{I}}$ is higher for films at "low" bubbling rates. This can be explained on the basis of well known size effect in ion conducting composites where the interface area is responsible for providing the ion conduction path and which increases as the particle size decreases.

\section{Conclusions}

Hence, we have successfully prepared the $\mathrm{PbS}$ nano particles in the PEO - polymer electrolyte matrix using chemical sulfuration method. A size distribution of particles was observed in XRD/SEM which were supported by UV/VIS 
optical absorption spectra and TEM micrographs. Low salt concentration and bubbling rate was found to be suitable for the formation of smaller (nano) particulates of $\mathrm{PbS}$. Further we have shown that the doping of semiconductor could be a novel approach to modify the electrical properties of polymer electrolytes.

\section{ACKNOWLEDGEMENTS}

This work is supported by DST project (SR/S 2/CMP-0065/2010) government of India.

\section{REFERENCES}

[1] Henglien A., 1989, Small-particle research: physicochemical properties of extremely small colloidal metal and semiconductor particles, Chem. Rev., 89, 1861-1873

[2] Ramsden J J, and M. Grätzel. M, 1984, Photoluminescence of small cadmium sulphide particles, J. Chem. Soc., Faraday. Trans., 80, 919-933

[3] Radhakrishnan. S, 1994, Polymer induced crystallization III. PEO-CdCl2 and in situ formation of PEO-CdS composite, J. Crystal Growth, 141, 437-442

[4] Braun P V, Osenar P, and Stupp S I, 1996, Semiconducting superlattices templated by molecular assemblies, Nature, $380,325-328$

[5] Nanda K K and Sahu S N, 2001, One-dimensional quantum confinement in electrodeposited $\mathrm{PbS}$ nanocrystalline semiconductors, Adv. Mater., 13, 280-283

[6] Steigerwald M L, Brus L E, 1990, Semiconductor Crystallites: A Class of Large Molecules, Ace. Chem. Res., 23, 183-188

[7] Lippens P E, and Lannoo M, 1989, Calculation of the band gap for small $\mathrm{CdS}$ and $\mathrm{ZnS}$ crystallites,Phys. Rev. B, 39, 10935-10942

[8] Lu X, Zhao Y, Wang C, 2005, Fabrication of PbS Nanoparticles in Polymer-Fiber Matrices by Electrospinning, Adv. Mater., 17, 2485-2488
[9] Luccio T D, Laera A M, Tapfer L, Kempter S, Kraus R, and Nickel B, 2006, Controlled nucleation and growth of CdS nanoparticles in a polymer matrix, J. Phys. Chem. B, 110, 12603-12609

[10] Arachchige I U and Brock S L, 2007, Highly Luminescent Quantum-Dot Monoliths, J. Am. Chem. Soc., 129, 1840-1841

[11] Maity R, Maiti U N, Mitra M K, Chattopadhyay K K, 2006, Synthesis and optical characterization of polymer-capped nanocrystalline $\mathrm{ZnS}$ thin films by chemical process, Physica E, 33, 104-109

[12] Watt A A R, Blake D, Warner J H, Thomsen E L, Tavenner E L, Dunlop H R and Meredith P, 2005, Lead sulfide nanocrystal: conducting polymer solar cells, J. Phys. D: Appl. Phys., 38, 2006-2012

[13] Brinkman W.F., Haggan D.E., Troutman W.W., 1997, A history of the invention of the transistor and where it will lead us, IEEE Journal of Solid - State Circuits, 32, 1858-1865

[14] Maurya K K, Srivastava N, Hashmi S A, Chandra S, 1992 , Proton conducting polymer electrolyte: II poly ethylene oxide + NH41 system, J. Mater. Sci., 27, 6357-6364

[15] Chandra A, Singh P K, Chandra S, 2002, Semiconductor-dispersed polymer electrolyte composites, Solid State Ionics, $154-155,15-20$

[16] Sze S M 1969 Physics of Semiconductor Devices (New York: Wiley Interscience)

[17] Stokes, A.R. and Wilson, A.J.C., 1944, A method of calculating the integral breadths of Debye-Scherrer lines: generalization to non-cubic crystals, Mathematical Proceedings of the Cambridge Philosophical Society, 40, 197-198

[18] Denton R, Muhlschlegal B and Scalapino D J, 1973, Thermodynamic Properties of Electrons in Small Metal Particles, Phys. Rev. B, 7, 3589-3607

[19] Arutyunyan V.A.,Aramyan K.S. and Petrosyan G.S., 2004, Quantum confined stark effect and electroabsorption in semiconductor spherical layers, Semiconductors, 38, 335-339

[20] Brus L E, 1983, Simple Model for the Ionization Potential, Electron Affinity, and Aqueous Redox Potentials of Small Semiconductor Crystallites, J. Chem. Phys., 79, 5566-5571 